\section{Oral warty dyskeratoma: An unusual presentation}

Hamid Reza Ghasemi Basir, ${ }^{1}$

Pedram Alirezaei, ${ }^{2}$

Bahareh Ebrahimi, ${ }^{2}$ Sina Khanali'

${ }^{1}$ Department of Pathology, School of

Medicine, Hamadan University of

Medical Sciences; ${ }^{2}$ Psoriasis Research

Center, Hamadan University of Medical

Sciences, Hamadan, Iran

\begin{abstract}
Warty dyskeratoma is an uncommon benign skin lesion, which is mostly limited to the head or neck and is rarely seen in other areas of the skin or mucous membranes. Although it is clinically similar to many skin lesions, its distinctive histopathologic features help distinguish it from other identical lesions. Herein, we report a case of warty dyskeratoma in a very unusual site (lateral border of the tongue) in a 56-year-old woman.
\end{abstract}

\section{Introduction}

Warty dyskeratoma is a benign proliferative epidermal disorder, which originates from the pilosebaceous unit. ${ }^{1}$ It was first introduced as isolated Darier disease, while in 1957, it was distinguished because of its distinctive histopathologic characteristics. ${ }^{2}$ It presents as a skin-colored to gray-pink umbilicated papule, with a keratin-filled center. It is often a single lesion involving the face or neck, although it has been rarely found in other areas, including the nails, hard palate, and genitalia. ${ }^{3}$ In histopathology, it appears as a distinct endophytic or exophytic epidermal lesion, which involves at least one pilosebaceous unit. In this type of lesion, epidermis is hyperplastic and cupshaped with a keratin-filled center, and suprabasal acantholysis and dyskeratotic cells are observed. Moreover, necrotic keratinocytes appear as corps ronds and grains similar to Darier disease. ${ }^{4}$

\section{Case presentation}

A 56-year-old woman was referred to our clinic with a six-month history of an asymptomatic mass with a central hole on the right side of the tongue, which was resistant to various topical therapies. Examinations showed a relatively firm pink to white nodule $(1.5 \times 1.5 \mathrm{~cm})$ on the right side of the tongue, which was slightly tender upon palpation (Figure 1). Further examination of systemic physical disorders and local trauma was unremarkable. The lesion was biopsied with differential diagnosis of oral papilloma, Squamous Cell Carcinoma (SCC), and chronic ulcer. The tissue sample was sent to a pathologist for further evaluation.

Pathological examination revealed a hyperplastic mucosal tissue with central invagination, which contained numerous acantholytic and dyskeratotic cells in the upper portion. The lower portion of the invagination was occupied by numerous villi, which were markedly elongated papillae, lining a single layer of basal cells. Chronic inflammation was observed in the underlying fibrotic stroma. The observations were compatible with warty dyskeratoma of oral mucosa. However, there was no classic presentation of a parakeratin plug (Figures 2-4).

\section{Discussion}

Warty dyskeratoma is a rare benign condition, arising from the pilosebaceous unit. It presents as a slow-growing, skincolored, umbilicated epidermal papule or nodule of variable size (from a few millimeters up to $3 \mathrm{~cm}$ ). It was initially described as isolated Darier disease, while it was distinguished later because of its distinctive pathological features. ${ }^{2}$ It is often reported in middle-aged adults, with a slight male predilection. $^{3}$

The etiology of warty dyskeratoma is unknown. Oral mucosa has no piloseaceous unit, and ectopic sebaceous glands, which are present in the buccal mucosa, are associated with oral warty dyskeratoma. Considering the irrelevance of these mucosal lesions to the pilosebaceous unit, some researchers believe that they should not be classified as warty dyskeratoma and use the term "focal isolated acanthlytic dyskeratosis". ${ }^{3}$ In some cases, oral mucosal traumas, such as biting and tobacco use, are suggested as risk factors. ${ }^{5}$

Mucosal warty dyskeratoma is a very rare condition, with only 50 reported cases. It presents as a whitish centrally umbilicated papule or nodule on the keratinized mucosa. However, this presentation is not consistent with cutaneous warty dyskeratoma, which is predominantly a skin-colored nodule with a rolled smooth edge and a hyperkeratotic central plug. ${ }^{6}$ Cutaneous
Correspondence: Pedram Alirezaei; Psoriasis Research Center, Farshchian Hospital, Mirzadeh Eshghi St., Hamadan, Iran

Tel.: +98-9128112916 - Fax: +988138272154; E-mail: prc@umsha.ac.ir

Key words: Warty dyskeratoma; acantholysis; histopathology.

Conflict of interests: The authors declare no potential conflict of interests.

Ethical approval and consent to participate: Written informed consent was obtained from the patient.

Received for publication: 8 July 2019.

Accepted for publication: 27 May 2020

This work is licensed under a Creative Commons Attribution-NonCommercial 4.0 International License (CC BY-NC 4.0).

${ }^{\circ}$ Copyright: the Author(s), 2020

Licensee PAGEPress, Italy

Dermatology Reports 2020; 12:8236

doi:10.4081/dr.2020.8236

warty dyskeratoma is mostly found on the head, neck, trunk, or extremities. ${ }^{7}$ Intraoral warty dyskeratoma is usually observed on keratinized mucosa, including maxillary and mandibular alveolar ridges and the hard palate. ${ }^{1}$ In our case, warty dyskeratoma was located on the right side of the tongue.

Warty dyskeratoma is typically asymptomatic in both cutaneous and mucosal sites. However, it may be associated with bleeding or central drainage. ${ }^{8}$ Allon and Buchner $^{3}$ published a review of oral warty dyskeratoma and reported 41 cases, including a lesion on the buccal mucosa of an 81year-old woman. Steele et al. also described a case of warty dyskeratoma on the buccal mucosa of a 60-year-old white man. ${ }^{6}$

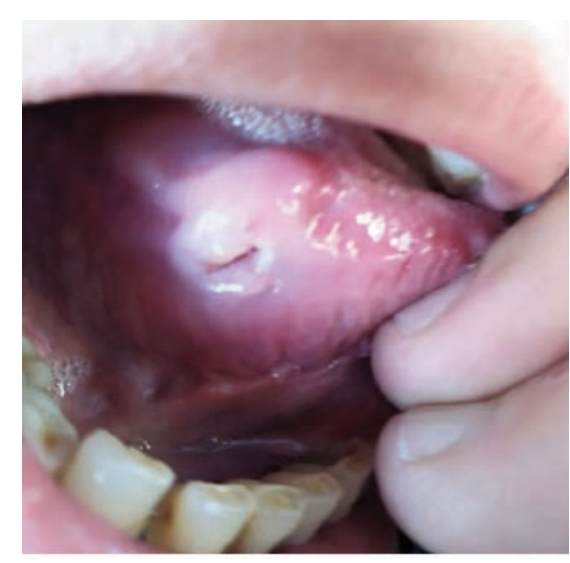

Figure 1. A firm pink-to-white ulcerated nodule on the right side of the tongue. 


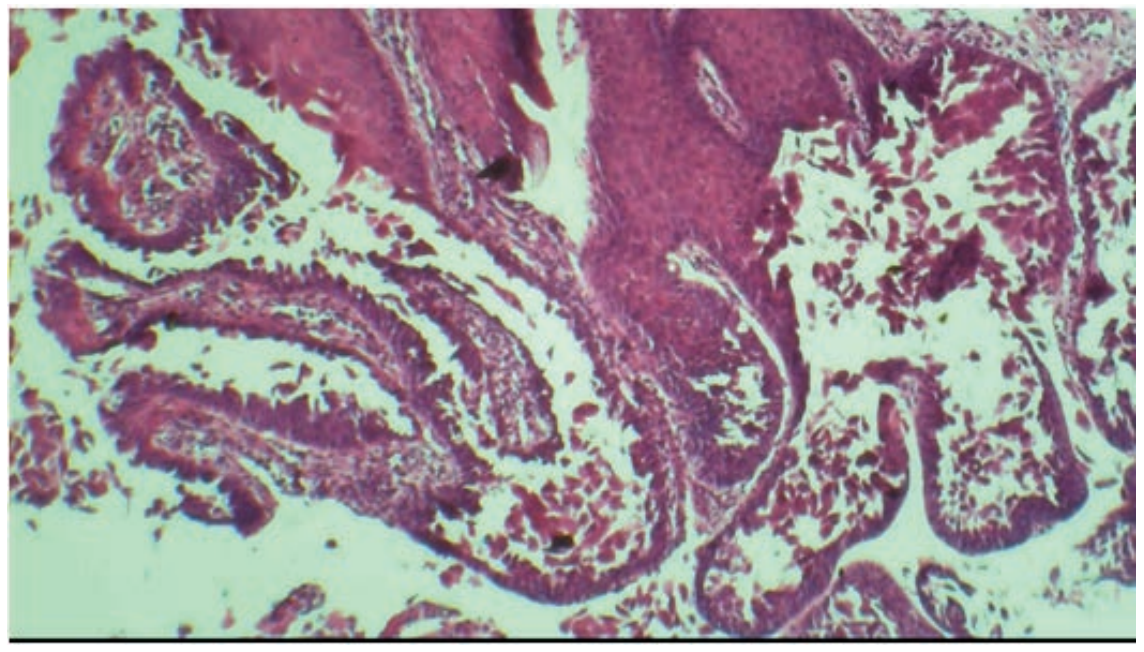

Figure 2. The image shows a hyperplastic mucosal tissue with central invagination connected to the surface (hematoxylin and eosin staining; 100X magnification).

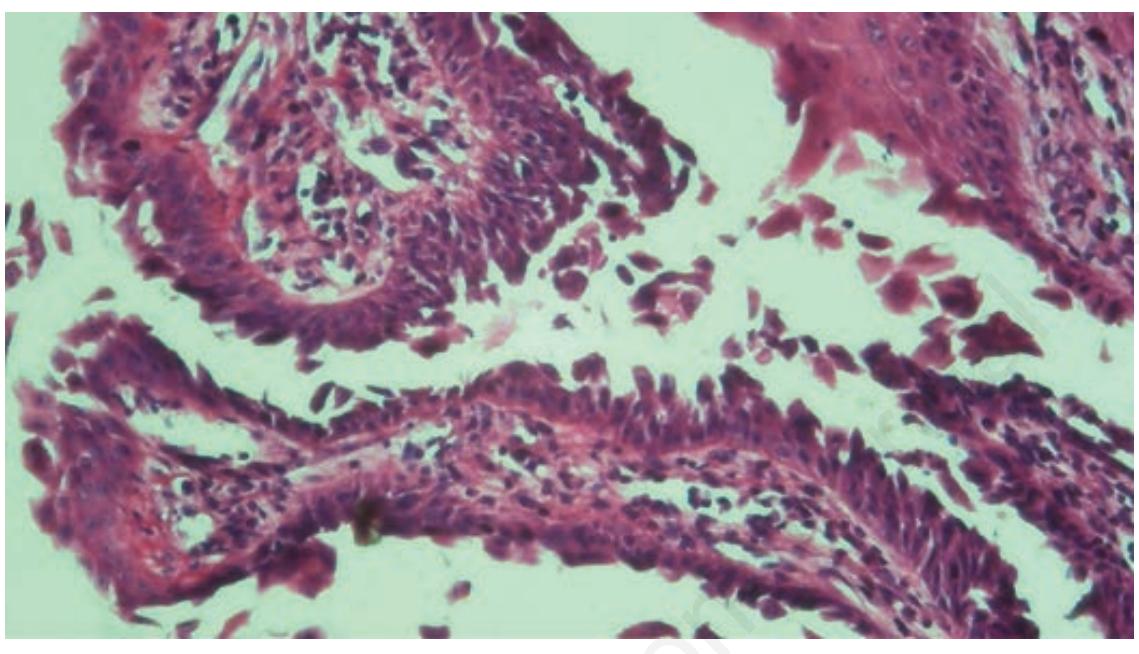

Figure 3. The image shows numerous villi composed of elongated papillae, which were lined with a single layer of basal cells, projected upward from the base of invagination (hematoxylin and eosin staining; 200X magnification).

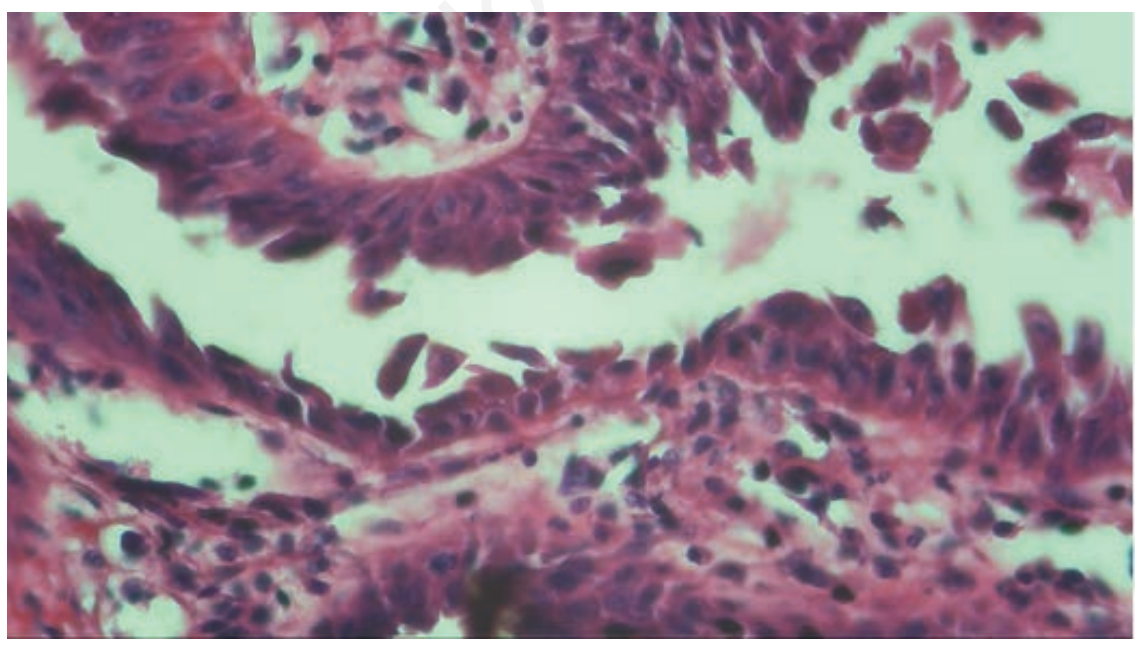

Figure 4. The image shows high magnification of villi structures in the bullous space with acantholytic and dyskeratotic cells (hematoxylin and eosin staining; 400X magnification).
Furthermore, Ugras et al. reported warty dyskeratoma-like lesions on the skin of the scalp and face of a 55-year-old woman; however, the patient was finally diagnosed with Darier disease. ${ }^{7}$ Peters et al. also described a case of warty dyskeratoma $(0.4$ $\mathrm{cm}$ ) in a 78-year-old man on the left retromolar trigone with mild tenderness on palpation. $^{9}$

In order to distinguish oral warty dyskeratoma from similar lesions, such as SCC, keratoacanthoma, and Darier disease, histopathological evaluation is necessary. Although it may mimic SCC because of its verruciform appearance and chronic ulceration, it is histologically distinguishable, as there is no atypia or mitotic activity in warty dyskeratoma. SCC does not have a cupshaped appearance. ${ }^{10}$ On the other hand, keratoacanthoma appears as a cup-shaped lesion, but does not show dyskeratosis and does not occur inside the mouth. ${ }^{3}$ Darier disease is usually associated with multiple lesions, while oral mucosa has a cobblestone appearance in oral Darier disease. In addition, no mutation of $A T P 2 A 2$ gene has been found in oral warty dyskeratoma. ${ }^{11}$ First-line treatment of warty dyskeratoma is excision of lesion by surgery. Regarding the benign nature of this lesion, complete excision is easily performed after confirming the diagnosis. It should be noted that there is no risk of recurrence or malignancy in patients with this type of lesion. ${ }^{5}$

\section{References}

1. Kaddu S, Dong H, Mayer G, et al. Warty dyskeratoma-"follicular dyskeratoma": analysis of clinicopathologic features of a distinctive follicular adnexal neoplasm. J Am Acad Dermatol 2002;47:423-8.

2. Szymanski FJ. Warty dyskeratoma: a benign cutaneous tumor resembling Darier's disease microscopically. Arch Dermatol 1957;75:567- 72.

3. Allon I, Buchner A. Warty dyskeratoma/focal acantholytic dyskeratosis - an update on a rare oral lesion. J Oral Pathol Med 2012;41:261-7.

4. Omulecki A, Lesiak A, Narbutt J, et al. Plaque form of warty dyskeratomaacantholytic dyskeratotic acanthoma. J Cutan Pathol 2007;34:494-6.

5. Kaugars GE, Lieb RJ, Abbey LM. Focal oral warty dyskeratoma. Int J Dermatol 1984;23:123-30.

6. Steele JC, Dutton AR, Triantafyllou A, Rajlawat BP. Warty dyskeratoma of the buccal mucosa. Oral Surg. 2014; 7:2368. 
7. Ugras N, Adim SB, Kilicoglu M, Baskan EB. Multiple warty dyskeratomas: case report. Iranian J Publ Health 2014;43:1145-7.

8. Tanay A, Mehregan AH. Warty dyskeratoma. Dermatologica 1969;138:15564.
9. Peters SM, Roll KS, Philipone EM, Yoon AJ. Oral warty dyskeratoma of the retromolar trigone: An unusual presentation of a rare lesion. JAAD Case Rep 2017;3:336-8.

10. Chau MN, Radden BG. Oral warty dyskeratoma. J Oral Pathol 1984;13:
546-56.

11. Sakuntabhai A, Ruiz-Perez V, Carter S, et al. Mutations in ATP2A2, encoding a $\mathrm{Ca} 2+$ pump, cause darier disease. Nat Genet 1999;21:271-7. 